\title{
Tyrphostin AG 370
}

National Cancer Institute

\section{Source}

National Cancer Institute. Tyrphostin AG 370. NCI Thesaurus. Code C2028.

A member of the Tyrphostin family of tyrosine kinase inhibitors that inhibits platelet derived growth factor (PDGF), autophosphorylation and PDGF-induced mitogenesis in fibroblast. $(\mathrm{NCl})$ 